\section{Checking up on Health Check}

Published at www.cmaj.ca on Jan. I7, 2008.

 hey seem at first a saving grace for parents of picky eaters: a source of calcium, made with whole wheat, low in saturated and trans fats; iGor muffins look and taste like chocolate Twinkies. On the front of the package, a cartoon gorilla grins at children wandering the grocery aisles with their parents. The box's upper right-hand corner displays the Heart and Stroke Foundation of Canada's "Health Check" logo.

The nutrition information on the back of the package reveals - in much smaller print - that the muffins are almost one-third sugar.

iGor muffins are one of several Health-Checked products a Canadian obesity expert is up in arms about. The Heart and Stroke Foundation of Canada wants Health Check to become part of a mandatory national food labeling policy, but Dr. Yoni Freedhoff, the medical director of the Ottawa-based Bariatric Medical Institute, says putting the seal of approval on foods that are high in sugar or sodium, or that contain red meat or refined flours, is a betrayal of the trust Canadians place in the Foundation.

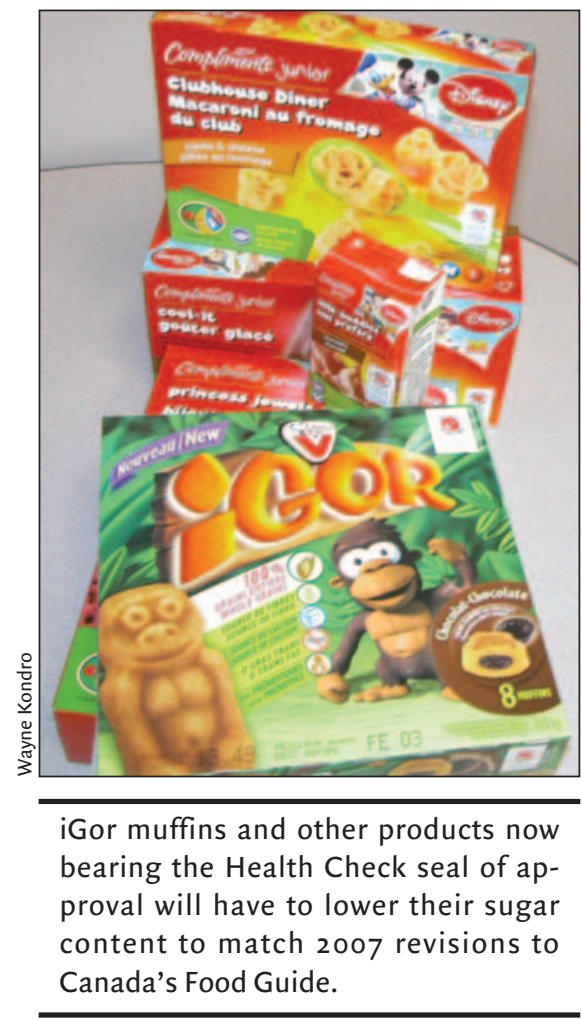

"As much as muffins and cookies are a delicious part of our lives, to try and tell people that they're a healthy choice in our diet is just madness," Freedhoff says.

He particularly objects to Health Check items in the Compliments Junior Disney-line of foods, which includes items like Mickey Mouse-shaped beef burgers, letter-shaped tater tots, and sweetened, flavoured "Milk Buddies."

"There is more sugar and more calories than Coca-Cola in these beverages that they're marketing with Disney characters to children as healthy choices," Freedhoff says. "Parents will think, 'This is great, I'm going to give these to my kids.' Basically, they're just shoveling sugar into their mouths."

The Heart and Stroke Foundation of Canada charges licensing fees for inclusion in Health Check, which requires that products meet nutrient criteria based on Canada's Food Guide to Healthy Eating. Terry Dean, the general manager of Health Check, says the fees allow the program to be self-supporting (Box I). As of last fall, there were I225 products bearing the Health Check logo.

Dean says the program is lowering the amounts of acceptable added sugar to match 2007 revisions to the food guide. iGor muffins are one of many products that will have to change in order to meet the new criteria. "We're giving people time to reformulate, because we don't want them defaulting to higher levels and going out of the program, so our hope is that they can do it."

But it's not just sugar and calories that make the program questionable, Freedhoff says. The World Cancer Research Fund released a report in early November linking the consumption of red and processed meats with cancer, but Health Checks still appear on lunch meats and lean beef.

Stephen Samis, the Heart and Stroke Foundation of Canada's director of health policy, takes issue with Freedhoff's interpretation of the cancer report, which "did not say, 'don't eat red meat. It said, 'limit your consumption of red meat,' and it said 'limit your consumption to something like 4-5 servings per week."”

Millions of Canadians eat red meat, he says. "So what we've done is said, look, if you're going to eat red meat, this is the

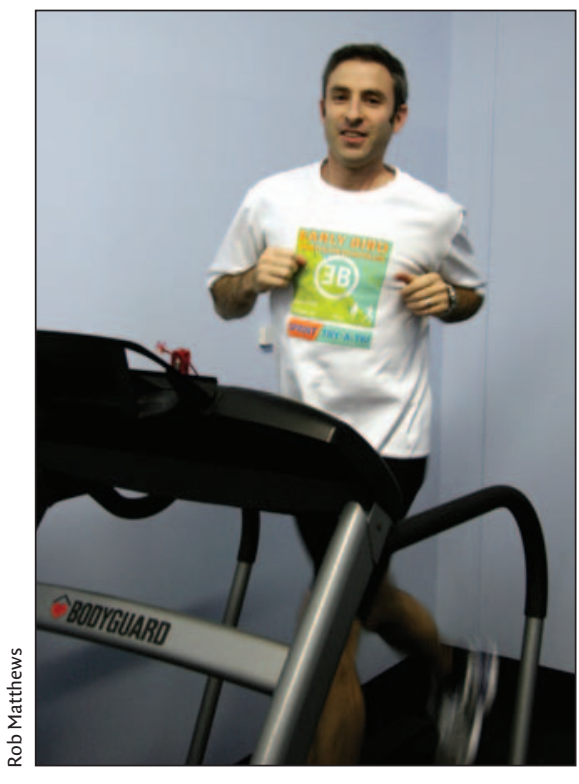

Dr. Yoni Freedhoff, Ottawa-based specialist in obesity medicine, seen here jogging on the office treadmill, believes that parents are often "shovelling sugar" into the mouths of their children when they indulge them with some foods bearing The Heart and Stroke Foundation of Canada's "Health Check" imprimatur.

kind of red meat that we recommend you eat - red meat that is lean or extra lean."

Last fall, the Foundation endorsed a national Sodium Policy Statement released by Blood Pressure Canada, which says that about I million Canadians have hypertension as a result of salt consumption levels. The statement recommended consuming between I 200 and $2300 \mathrm{mg}$ of sodium per day; the average Canadian consumes about $3500 \mathrm{mg}$.

It would be easy to eat a whole days' worth of sodium in I meal at Boston Pizza, eating only Health Checked menu items. The lime and parmesan shrimp skewers appetizer, for example, has IIIo mg of sodium. The Thai chicken wrap has II8o mg.

But Samis says the sodium content in Health Checked products is generally lower than in comparable items, and the Foundation is gradually reducing the allowable amount of sodium. "The sodium policy statement talked about getting Canadians down to $1500 \mathrm{mg}$ per day by 2020 , not by tomorrow, and that's very important. ... It takes time to adjust the consumer palate downward. Canadians eat a lot of sodium. They're 
used to eating a lot of sodium. They expect their food to have a certain taste and texture, and sodium is part of that."

That's not good enough, Freedhoff counters. "You just can't have it both ways. You can't say that we should reduce sodium and then recommend products high in sodium."

Freedhoff says part of the problem is that Health Check is based on the food guide, which he believes is heavily influenced by the beef, dairy and restaurant industries (CMAJ 2006;174[5]:605-6 and $C M A J$ 2007;176[6]:752-3). "I'm not sure it would look good for the number 3 beef-producing country in the world to say, 'beef's not good for you.' Canada's got a $\$ 20$ billion dairy industry. It's going to be a difficult thing to say we should be drinking less milk."

The Heart and Stroke Foundation's adherence to the food guide could be politically motivated, linked to its attempts to get Health Check included in a national front-of-package labelling program, Freedhoff surmises. "I don't think that we could have a national program sponsored by our government that was at odds with our food guide."

But not all nutrition experts agree with Freedhoff's condemnation of food guide's recommendations as "nutritionally indefensible."

Registered Dietitian Claire Cronier has mixed feelings about Health Check. "I believe that one has to look at a total diet rather than singling out individual foods. Everybody's going to have a stan-

\section{Box 1: Primary features of the Health Check program}

Created in 1999 by the Heart and Stroke Foundation of Canada as a quick means of identifying foods and restaurant menu items that meet nutrient criteria based on Canada's Food Guide, the program aims to help Canadians make healthy food choices. "It's like shopping with the Heart and Stroke Foundation's dietitians," organizers say.

\section{Procedures}

Food manufacturers or restaurants submit applications for Health Check approval for a specific product or menu item. Applications must include a nutrient analysis.

Applications are reviewed by Foundation dietitians and evaluated against specific Health Check serving sizes. Those who meet the test are issued a licence to use the Health Check symbol on their labels or menus.

\section{Criteria}

Criteria are established by a Health Check Technical Advisory Committee "made up of dietitians and nutritional experts from across the country."

Nutrient criteria (available at healthcheck.org) are fairly extensive. They were revised in mid-January, with the changes to take effect in December 2009 for existing products, and immediately for new ones. Generally, a product must meet "entry-level" maximums for total fat, saturated fat, protein and sodium content.

For example, a 55-g serving of a breakfast cereal must have low or no added fat ( $3 \mathrm{~g}$ or less), have at least $2 \mathrm{~g}$ of fibre and a sodium level under $480 \mathrm{mg}$. Under recent revisions, the cereal will also have to meet the tests of having less than $11 \mathrm{~g}$ of sugars "excluding sugars from pieces of fruits except if $6 \mathrm{~g}$ or more fibre," while having a trans fat ratio of less than $5 \%$ of its total fat content.

Fees

Applicants pay a 1-time evaluation fee and an annual licensing fee, both of which are pegged to a sliding scale based on the nature of the product and "the size of the market."

The evaluation fee ranges from $\$ 150$ to $\$ 750$. The annual licensing fee ranges from $\$ 1225$ to $\$ 3625$. Discounts are available to companies offering multiple products. A company with 14 or more products pays a maximum annual fee of $\$ 16500$ to $\$ 49500$, depending upon the food category. Companies that reach the maximum 14 in 4 different categories pay a maximum $\$ 66000$ to $\$ 180000$, again depending on the specific food categories that their products fall under. Health Check spokesperson Danielle Côté says that translates into gross revenues of \$2.6 million per year.

Source: The Heart and Stroke Foundation of Canada.

dard or a number, and we're always going to argue whether that number is high or low. ... I think Heart and Stroke is doing the best they can, in terms of probably being the strictest out there."

Cronier also acknowledges that healthy choices are invariably easier for a dietitian than for the average consumer. "Some consumers are really looking for that little logo or check or whatever to reinforce their choice so they don't have to think about it."

Samira Barakat, a mother of 2 who works at Winners, notices the Health Check on certain foods, but also pays attention to nutrition information on the back of packages. "I always check. I don't go by the picture," she says.

Retired teacher Norma Dowdles is similarly skeptical. "Having seen this label [points at Health Check logo] and this label together [points at "V" for Vachon brand name on iGor muffins)," Dowdles says "I would probably make my own judgment, to be honest."

For them, the issue is not clear-cut.

For Freedhoff, it is. "This is so - for me anyhow - black and white wrong." But he emphasizes that his problem is with Health Check, not the foundation. "I think it's a great organization. So, I want to be very clear: I'm not bashing them, but I am bashing Health Check because it's just not what we understand to be true about diet and nutrition, and it promotes the very diseases that the Heart and Stroke Foundation is supposed to be rallying against."

Samis respects Freedhoff's passion and concern for Canadians' health, but adds that "he's not the sole arbiter of healthy eating in the country. He hates Canada's Food Guide. We respect that. We don't necessarily agree with him, but the food guide was established by hundreds of experts."

"It's important that there are people in the country who are encouraging people to eat as healthfully as possible. We feel that that's exactly what we do as part of the Heart and Stroke Foundation as well, and feel really that we're actually trying to achieve the same kinds of things," Samis adds. "At the end of the day, the ends are the same." - Amanda Truscott, Ottawa, Ont. 